\title{
LINEAR SEARCH VERSUS BINARY SEARCH: A STATISTICAL COMPARISON FOR BINOMIAL INPUTS
}

\author{
Anchala Kumari ${ }^{1}$, Rama Tripathi ${ }^{2},{\text { Mita } \mathrm{Pal}^{3} \text { and Soubhik Chakraborty }}^{4 *}$ \\ ${ }^{1}$ University Department of Statistics, Patna University, Patna-800005, India \\ ${ }^{2}$ Department of Information Technology, BIT Mesra, Ranchi-835215, India \\ ${ }^{3,4}$ Department of Applied Mathematics, BIT Mesra, Ranchi-835215, India \\ *corresponding author's email: soubhikclyahoo.co.in (S. Chakraborty)
}

\begin{abstract}
For certain algorithms such as sorting and searching, the parameters of the input probability distribution, in addition to the size of the input, have been found to influence the complexity of the underlying algorithm. The present paper makes a statistical comparative study on parameterized complexity between linear and binary search algorithms for binomial inputs.
\end{abstract}

\section{KEY WORDS}

Linear search; binary search; parameterized complexity; statistics; factorial experiments

\section{INTRODUCTION}

Two of the popular search algorithms are linear search and binary search. While linear search (also called sequential search) scans each array element sequentially, a binary search in contrast is a dichotomic divide and conquer search algorithm. For an extensive literature on searching, see Knuth [1].

In the present paper we investigate the effect of parameters $n$ and $p$ of a Binomial distribution input on the number of comparisons in linear search and binary search. Using factorial experiment, it is observed that both the main effects $n$ and $p$ and the interaction effects $n^{*} p$ are highly significant for linear and significant but comparatively less for binary search. The result clearly suggests that apart from the size of the input, the parameters of the input distribution need also be taken into account to explain the behavior of certain algorithms. In an earlier work on parameterized complexity, Anchala and Chakraborty [2] used factorial experiment to explain software complexity for insertion sort. The same authors have used factorial experiments with a

DOI : $10.5121 /$ ijcsea.2012.2203 
response surface design in [3] to examine the nature of the fast and popular quicksort. The first researchers to work on parameterized complexity are Downey and Fellows [4].

\section{Experimental results}

\subsection{Results using factorial experiment}

Binomial variates are independently filled in an array of size $\mathrm{k}=2000$ (fixed) and we make a linear search for an element which is in the array. We are interested in finding the number of comparisons expected to ascertain that the searched element is present. To ensure the searched element is indeed available in the array, one array index was randomly selected and the key of this index is the searched element. The code is omitted.

Binomial distribution (definition): Let $X$ be a Binomial variate with parameters $n$ and $p$. The probability $\mathrm{P}(\mathrm{X}=\mathrm{x})={ }^{\mathrm{n}} \mathrm{C}_{\mathrm{x}} \mathrm{p}^{\mathrm{x}}(1-\mathrm{p})^{\mathrm{n}-\mathrm{x}}$ where $\mathrm{x}=0,1,2, \ldots \mathrm{n}$ and $0<\mathrm{p}<1$. Binomial distribution has three assumptions:

1. Trials are independent.

2. Each trial can result in one of two possible outcomes which we call "success" and "failure" respectively.

3. The probability of success $p$ is fixed in each trial. The expression for $P(X=x)$ gives the probability of getting $\mathrm{x}$ successes in $\mathrm{n}$ trials made under the three above-mentioned assumptions. The distribution is so called as the expression for $\mathrm{P}(\mathrm{X}=\mathrm{x})$ is the general term, i.e., $(\mathrm{x}+1)$-th term in the Binomial expansion of $(q+p)^{n}, q=1-p$ is the probability of failure in each trial. Since we assume $\mathrm{p}$ as fixed, $\mathrm{q}$ is fixed as well. Further literature on Binomial distribution can be found in Gupta and Kapoor [5].

To study the main effects $n$ and $p$ as well as the interaction effects $n^{*} p$ of the parameters $n$ and $p$ of Binomial (n, p) distribution input on the number of comparisons, a $3^{2}$ factorial experiment was conducted with two factors $n$ and $p$ each at three levels $(3000,6000,9000$ for $n$ and 0.2, 0.5 and 0.8 for $\mathrm{p}$ ). Table 1 gives the data for the desired factorial experiment ( $\mathrm{n}$ is written as $\mathrm{N}$ and $\mathrm{p}$ as $\mathrm{P}$; this is what MINITAB will print) for linear search while table 2 gives the same for binary search. Tables 3 and 4 give the ANOVA tables depicting the results of factorial experiment on linear search and binary search respectively.

\subsection{Other experimental results}

Tables 5-8 and figures 1-8 summarize our other experimental results. These results were obtained for fixed array size $\mathrm{k}=2000$.

\section{Discussion}

It can be theoretically argued that the parameters of the Binomial distribution, in addition to the array size k (here fixed at 2000), will affect the number of comparisons in linear search (the same for binary search is under investigation). Since the searched element can be present in more than 
one place, we suppose the first time it comes is in position $r, r=1,2 \ldots k$. Then we must have that the first $r-1$ comparisons did not yield the searched element and that the $r$-th comparison yielded it.

Evidently, this probability is $\mathrm{P}(\mathrm{r})=\mathrm{C}\{1-\mathrm{f}(\mathrm{y}, \mathrm{n}, \mathrm{p})\}^{\mathrm{r}-1} \mathrm{f}(\mathrm{y}, \mathrm{n}, \mathrm{p}), \mathrm{r}=1,2 \ldots \mathrm{k} \ldots \ldots . .(1)$

where $\mathrm{y}$ is the searched element.

This is because the $\mathrm{k}$ array elements are independently filled with Binomial $(n, p)$ variates, so that the probability of any array element to be $\mathrm{y}$ is $\mathrm{P}(\mathrm{X}=\mathrm{y})=\mathrm{f}$ (say) and not to be $\mathrm{y}$ is $1-\mathrm{f}$. $\mathrm{C}$ is a normalization factor to ensure $\Sigma \mathrm{P}(\mathrm{r})=1, \mathrm{r}=1,2 \ldots \mathrm{k}$ It can be shown that the expected number of comparisons

$=\mathrm{E}(\mathrm{r})=\Sigma \mathrm{rP}(\mathrm{r})$, the summation over $\mathrm{r}$ is froml to $\mathrm{k},=\mathrm{C}$ f $\mathrm{S}$ where $\mathrm{C}=1 /[1-\mathrm{P}(0)-\mathrm{P}(\mathrm{k}+1)-$ $\mathrm{P}(\mathrm{k}+2) \ldots . .$.

$$
\begin{gathered}
f={ }^{n} C_{y} p^{x}(1-p)^{n-y} \\
\text { and, } \quad S=\left[1-\{1-f\}^{k}\right] / f^{2}-k\{1-f\}^{k} / f
\end{gathered}
$$

Remark: The random variable $\mathrm{r}$ follows a doubly truncated Geometric distribution since $\mathrm{r}$ cannot take the value 0 , nor can it take a value higher than $\mathrm{k}$.

The expression for the expected number of comparisons, however, does not establish the significance of the interaction effect $n^{*} \mathrm{p}$ and hence we resorted to factorial experiments. Our results confirm the interaction effect, besides the main effects, is highly significant. Further, figures 1-8 suggest an $\mathrm{O}(\mathrm{n})$ complexity for fixed $\mathrm{p}$ and $\mathrm{k}$ and $\mathrm{O}(\mathrm{p})$ complexity for fixed $\mathrm{n}$ and $\mathrm{k}$.

\section{Conclusion}

Using $3^{2}$ factorial experiment, it is observed that not only the main effects $n$ and $p$ but even the interaction effects $n * p$ are highly significant in influencing the number of comparisons in linear search for Binomial (n, p) input. However, it is also observed that the main effects $n, p$ and the interaction effects $\mathrm{n}^{*} \mathrm{p}$ are comparatively less significant in influencing the number of comparisons in binary search for Binomial (n, p) input.. Moreover, the mean comparisons seems to depend linearly on $\mathrm{n}$ and $\mathrm{p}$ for fixed $\mathrm{k}$. Interestingly, this is true for both linear and binary search. The results clearly suggest why, apart from the size of the input, the parameters of the input distribution need also be taken into account to explain the behavior of certain algorithms. The role of factorial experiments is firmly established in parameterized complexity analysis in such algorithms.

To the question which algorithms are better suited for such studies in parameterized complexity, the answer is that those in which fixing the input parameter characterizing the array size ( $\mathrm{k}$ in our case) does not fix all the computing operations. The sorting and searching algorithms fall into this category. Future work includes similar interesting case studies. 


\section{TABLES AND FIGURES}

Table 1: Mean number of comparisons in linear search for fixed array size (2000) and varying $\mathrm{N}$ and $\mathrm{P}$.

\section{First set of observations}

$\begin{array}{lrcr}\mathbf{P} & \mathbf{N}=\mathbf{3 0 0 0} & \mathbf{N = 6 0 0 0} & \mathbf{N = 9 0 0 0} \\ 0.2 & 119.92 & 515.02 & 967.79 \\ 0.5 & 112.47 & 581.42 & 1185.53 \\ 0.8 & 108.03 & 535.30 & 1022.51\end{array}$

Second set of observations

$\begin{array}{llcr}\mathbf{P} & \mathbf{N}=\mathbf{3 0 0 0} & \mathbf{N = 6 0 0 0} & \mathbf{N = 9 0 0 0} \\ 0.2 & 118.03 & 516.09 & 967.95 \\ 0.5 & 112.09 & 582.50 & 1184.36 \\ 0.8 & 107.56 & 533.40 & 1020.31\end{array}$

Third set of observations

$\begin{array}{lrrr}\mathbf{P} & \mathbf{N}=\mathbf{3 0 0 0} & \mathbf{N}=\mathbf{6 0 0 0} & \mathbf{N}=\mathbf{9 0 0 0} \\ 0.2 & 119.06 & 514.86 & 968.03 \\ 0.5 & 111.43 & 581.89 & 1186.46 \\ 0.8 & 108.98 & 536.20 & 1021.56\end{array}$

Table 2: Mean number of comparisons in binary search for fixed array size (2000) and varying $\mathrm{N}$ and $\mathrm{P}$.

First set of observations

$\begin{array}{lccc}\mathbf{P} & \mathbf{N}=\mathbf{3 0 0 0} & \mathbf{N}=\mathbf{6 0 0 0} & \mathbf{N = 9 0 0 0} \\ 0.2 & 1001.33 & 4019.86 & 7059.48 \\ 0.5 & 994.98 & 3934.99 & 6934.33 \\ 0.8 & 1034.68 & 4086.44 & 7029.36\end{array}$

Second set of observations

$\begin{array}{lrrr}\mathbf{P} & \mathbf{N}=\mathbf{3 0 0 0} & \mathbf{N}=\mathbf{6 0 0 0} & \mathbf{N}=\mathbf{9 0 0 0} \\ 0.2 & 975.69 & 4046.297054 .04 \\ 0.5 & 998.20 & 3966.216952 .95 \\ 0.8 & 982.34 & 4002.587058 .36\end{array}$

Third set of observations

$\begin{array}{lccc}\mathbf{P} & \mathbf{N}=\mathbf{3 0 0 0} & \mathbf{N}=\mathbf{6 0 0 0} & \mathbf{N}=\mathbf{9 0 0 0} \\ 0.2 & 1014.414032 .38 & 7019.08\end{array}$


International Journal of Computer Science, Engineering and Applications (IJCSEA) Vol.2, No.2, April 2012

$\begin{array}{lccc}0.5 & 1005.05 & 3966.83 & 6989.9 \\ 0.8 & 988.91 & 3991.40 & 7039.2\end{array}$

Table 3: Analysis of Variance for y, using Adjusted SS for Tests (linear search)

$\begin{array}{lrrrrrr}\text { Source } & \text { DF } & \text { Seq SS } & \text { Adj SS } & \text { Adj MS } & \text { F } & P \\ \mathrm{~N} & 2 & 4030817 & 4030817 & 2015409 & 2659942.28 & 0.000 \\ \mathrm{P} & 2 & 42272 & 42272 & 21136 & 27895.62 & 0.000 \\ \mathrm{~N}^{*} \mathrm{p} & 4 & 42014 & 42014 & 10504 & 13862.63 & 0.000 \\ \text { Error } & 18 & 14 & 14 & 1 & & \\ \text { Total } & 26 & 4115118 & & & & \\ \mathrm{~S}=0.870453 & \mathrm{R}-\mathrm{Sq}=100.00 \% & \mathrm{R}-\mathrm{Sq}(\mathrm{adj})=100.00 \%\end{array}$

MINITAB version 15 was used to yield the results of the factorial experiments of Linear search:-

\section{Multilevel Factorial Design}

Factors: 2 Replicates: 3

Base runs: 9 Total runs: 27

Base blocks: 1 Total blocks: 1

Number of levels: 3,3

\section{General Linear Model: y versus N, p}

$\begin{array}{lccc}\text { Factor } & \text { Type } & \text { Levels } & \text { Values } \\ \mathrm{N} & \text { fixed } & 3 & 1,2,3 \\ \mathrm{p} & \text { fixed } & 3 & 1,2,3\end{array}$

Table 4: Analysis of Variance for y, using Adjusted SS for Tests (binary search)

$\begin{array}{lrrrrrr}\text { Source } & \text { DF } & \text { Seq SS } & \text { Adj SS } & \text { Adj MS } & \text { F } & \text { P } \\ \mathrm{N} & 2 & 162847793 & 162847793 & 81423897 & 123575.44 & 0.000 \\ \mathrm{P} & 2 & 16681 & 16681 & 8340 & 12.66 & 0.000 \\ \mathrm{~N} * \mathrm{P} & 4 & 8489 & 8489 & 2122 & 3.22 & 0.037 \\ \text { Error } & 18 & 11860 & 11860 & 659 & & \\ \text { Total } & 26 & 162884823 & & & & \end{array}$


International Journal of Computer Science, Engineering and Applications (IJCSEA) Vol.2, No.2, April 2012

$\mathrm{S}=25.6691 \quad \mathrm{R}-\mathrm{Sq}=99.99 \% \mathrm{R}-\mathrm{Sq}(\operatorname{adj})=99.99 \%$

MINITAB version 15 was used to yield the results of the factorial experiments of binary search:-

Multilevel Factorial Design

$\begin{array}{lllr}\text { Factors: } & 2 & \text { Replicates: } & 3 \\ \text { Base runs: } & 9 & \text { Total runs: } & 27 \\ \text { Base blocks: } & 1 & \text { Total blocks: } & 1\end{array}$

Number of levels: 3, 3

\section{General Linear Model: y versus N, P}

$\begin{array}{lccc}\text { Factor } & \begin{array}{l}\text { Type } \\ \text { fixed }\end{array} & \text { Levels } & \text { Values } \\ \text { N } & 3 & 1,2,3 \\ \text { P } & \text { fixed } & 3 & 1,2,3\end{array}$

Table 5: Mean and SD of no. of comparisons for fixed $p=0.2$ and $N$ varying from 3000 to 9000

LINEAR SEARCH

BINARY SEARCH

\begin{tabular}{|c|c|c|c|c|}
\hline & Linear & & Binary & \\
\hline $\mathrm{N}$ & MEAN & SD & MEAN & SD \\
\hline 3000 & 95.42429 & 5.099625 & 971.1229 & 21.92183 \\
\hline 4000 & 211.8057 & 8.217798 & 1928.013 & 42.26884 \\
\hline 5000 & 340.4814 & 10.77158 & 2893.254 & 76.00657 \\
\hline 6000 & 483.5814 & 15.46534 & 3880.792 & 1111.529 \\
\hline 7000 & 632.7686 & 19.9731 & 4879.703 & 148.2382 \\
\hline 8000 & 820.7614 & 25.74744 & 5854.994 & 185.6159 \\
\hline 9000 & 971.8386 & 31.84307 & 6849.33 & 222.3924 \\
\hline
\end{tabular}


International Journal of Computer Science, Engineering and Applications (IJCSEA) Vol.2, No.2, April 2012

Table 6: Mean and SD of no. of comparisons for fixed $\mathrm{p}=0.5$ and $\mathrm{N}$ varying from 3000 to 9000

LINEAR SEARCH

\begin{tabular}{|l|l|l|l|l|l|}
\hline & Linear & & & Binary & \\
\hline $\mathrm{N}$ & MEAN & SD & & MEAN & SD \\
\hline 3000 & 130.1014 & 7.00651 & & 972.08 & 21.59409 \\
\hline 4000 & 264.1129 & 8.887761 & & 1980.031 & 42.77784 \\
\hline 5000 & 415.3614 & 13.31927 & & 2928.61 & 77.99048 \\
\hline 6000 & 588.0328 & 18.06139 & & 3899.347 & 112.9273 \\
\hline 7000 & 756.0186 & 24.04293 & & 4844.13 & 148.9676 \\
\hline 8000 & 924.8 & 26.66672 & & 5850.78 & 185.8966 \\
\hline 9000 & 1121.763 & 36.24661 & & 6819.733 & 222.2228 \\
\hline
\end{tabular}

Table 7: Mean and SD of no. of comparisons for fixed $\mathrm{p}=0.8$ and $\mathrm{N}$ varying from 3000 to 9000

LINEAR SEARCH

BINARY SEARCH

\begin{tabular}{|c|c|c|c|c|}
\hline 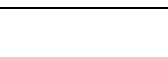 & Linear & & Binary & \\
\hline $\mathrm{N}$ & MEAN & SD & MEAN & SD \\
\hline 3000 & 115.6329 & 6.243703 & 1018.141 & 21.48802 \\
\hline 4000 & 245.1214 & 8.52181 & 1985.369 & 44.04666 \\
\hline 5000 & 393.5871 & 12.7249 & 2975.52 & 78.13666 \\
\hline 6000 & 550.3929 & 17.45485 & 3982.537 & 114.5793 \\
\hline 7000 & 704.8671 & 22.51765 & 4990.81 & 152.1838 \\
\hline 8000 & 856.3285 & 27.90663 & 5981.506 & 189.8659 \\
\hline 9000 & 1041.273 & 33.69814 & 7011.628 & 227.1954 \\
\hline
\end{tabular}


International Journal of Computer Science, Engineering and Applications (IJCSEA) Vol.2, No.2, April 2012

Table 8: Mean and SD of no. of comparisons for fixed $\mathrm{N}=10,000$ and $\mathrm{p}$ varying from 0.1 to 0.9

LINEAR SEARCH

BINARY SEARCH

\begin{tabular}{|c|c|c|c|c|}
\hline & Linear & & Binary & \\
\hline $\mathrm{P}$ & MEAN & SD & MEAN & SD \\
\hline 0.1 & 146.4986 & 8.256072 & 1007.9 & 21.96101 \\
\hline 0.2 & 312.5357 & 9.884373 & 2030.541 & 43.94901 \\
\hline 0.3 & 488.8714 & 14.8072 & 3028.646 & 79.62766 \\
\hline 0.4 & 683.6443 & 20.83033 & 4020.094 & 116.2303 \\
\hline 0.5 & 887.1243 & 27.49452 & 5019.079 & 153.6259 \\
\hline 0.6 & 1076.687 & 34.59078 & 6050.274 & 190.9012 \\
\hline 0.7 & 1289.791 & 42.12352 & 7076.607 & 229.6028 \\
\hline 0.8 & 1460.953 & 49.30895 & 8077.373 & 268.2914 \\
\hline 0.9 & 1601.191 & 55.57834 & 9095.618 & 305.9862 \\
\hline
\end{tabular}

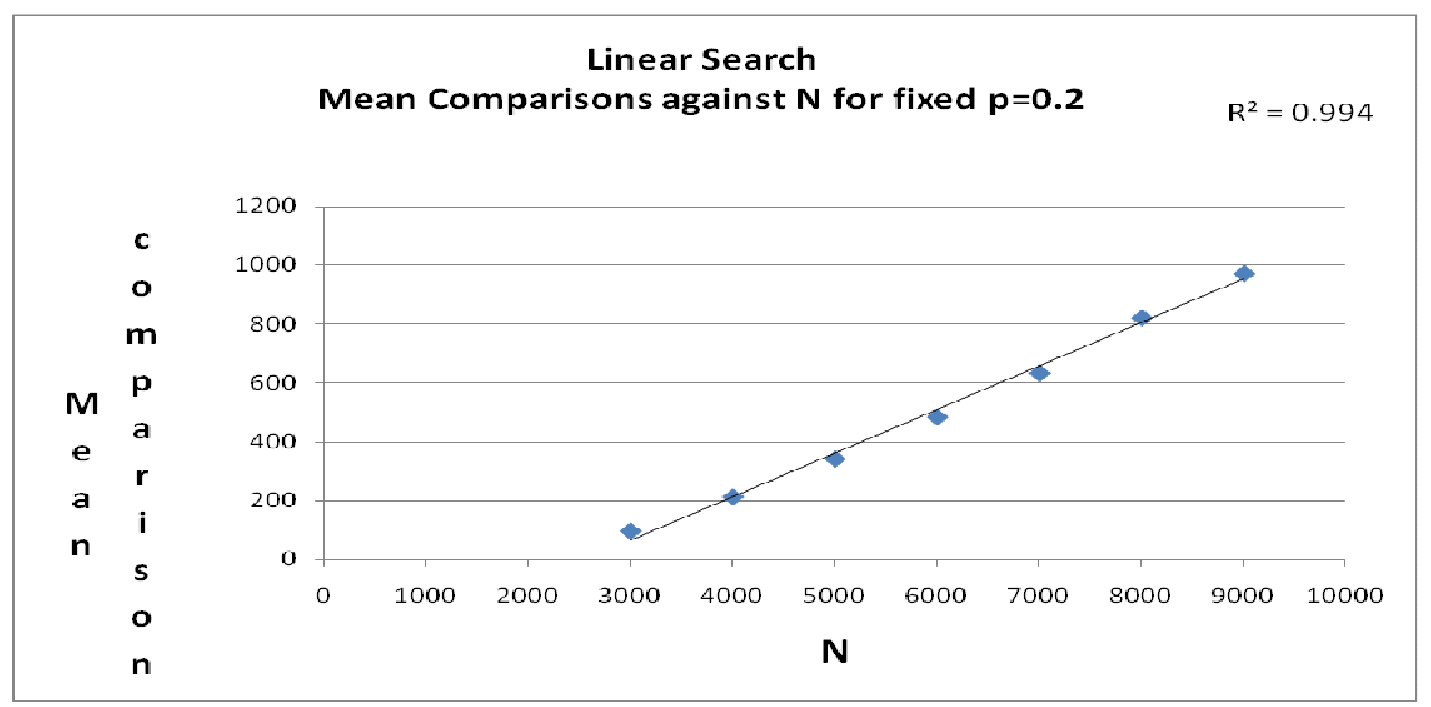

Fig. 1 Plot between $\mathrm{N}$ and Mean Comparisons for linear search $(\mathrm{p}=0.2)$ 
International Journal of Computer Science, Engineering and Applications (IJCSEA) Vol.2, No.2, April 2012

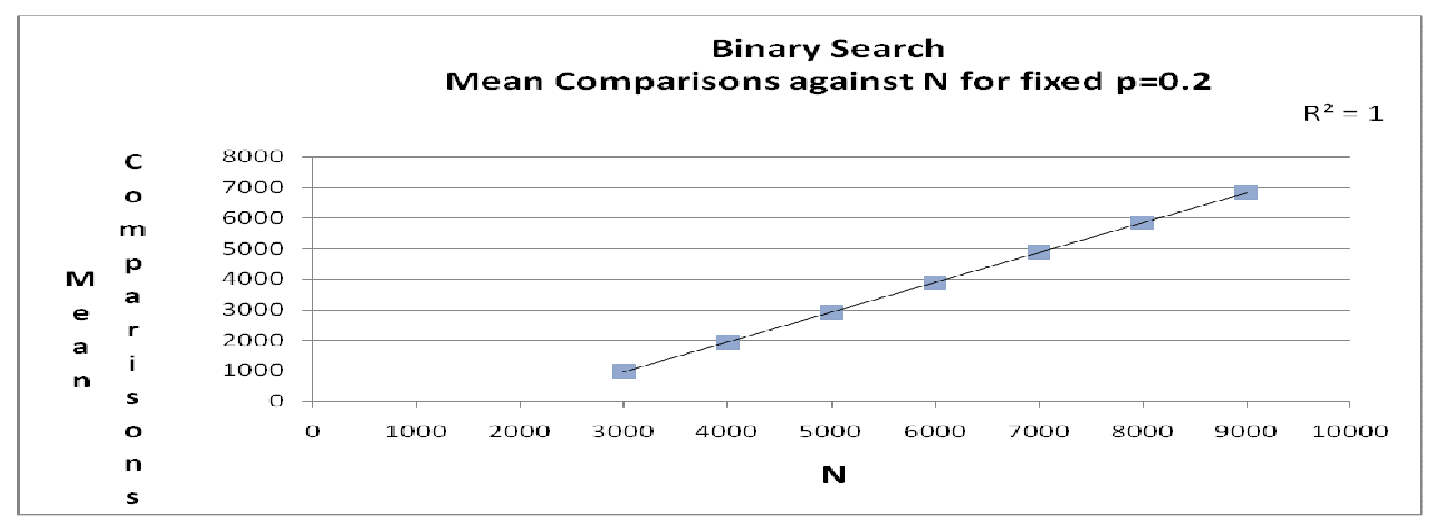

Fig. 2 Plot between N and Mean Comparisons for Binary Search $(p=0.2)$

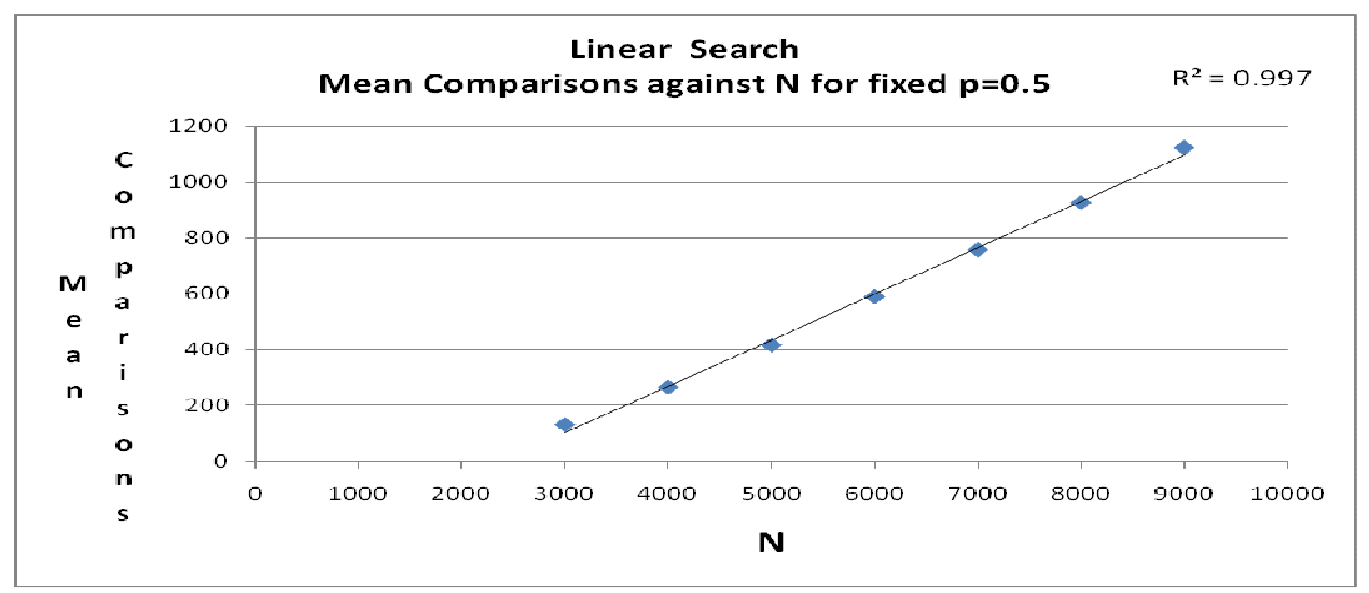

Fig. 3 Plot between $\mathrm{N}$ and mean comparisons for linear search $(\mathrm{p}=0.5)$ 
International Journal of Computer Science, Engineering and Applications (IJCSEA) Vol.2, No.2, April 2012

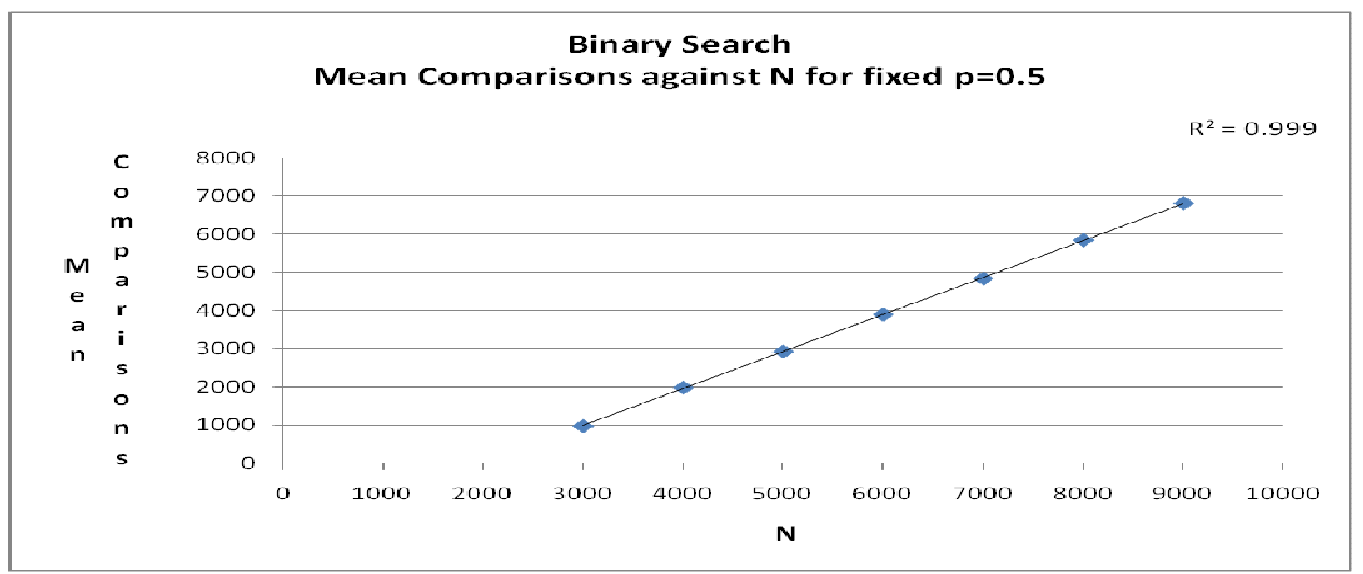

Fig. 4: Plot between $\mathrm{N}$ and mean comparisons for binary search $(\mathrm{p}=0.5)$

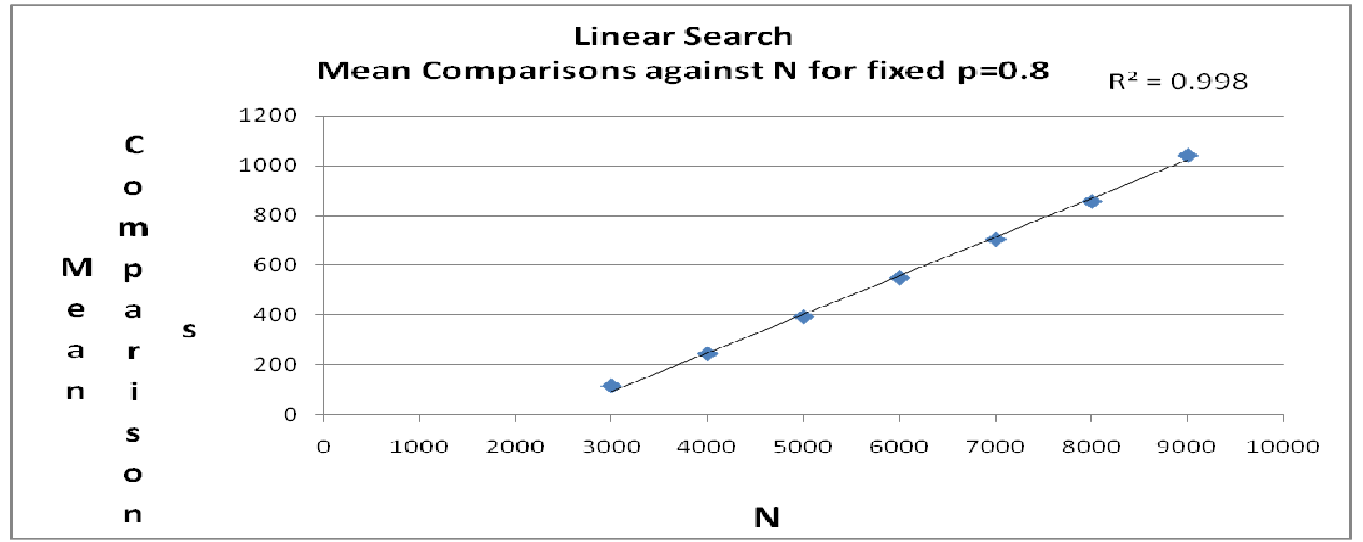

Fig. 5: Plot between $\mathrm{N}$ and mean comparisons for linear search $(\mathrm{p}=0.8)$

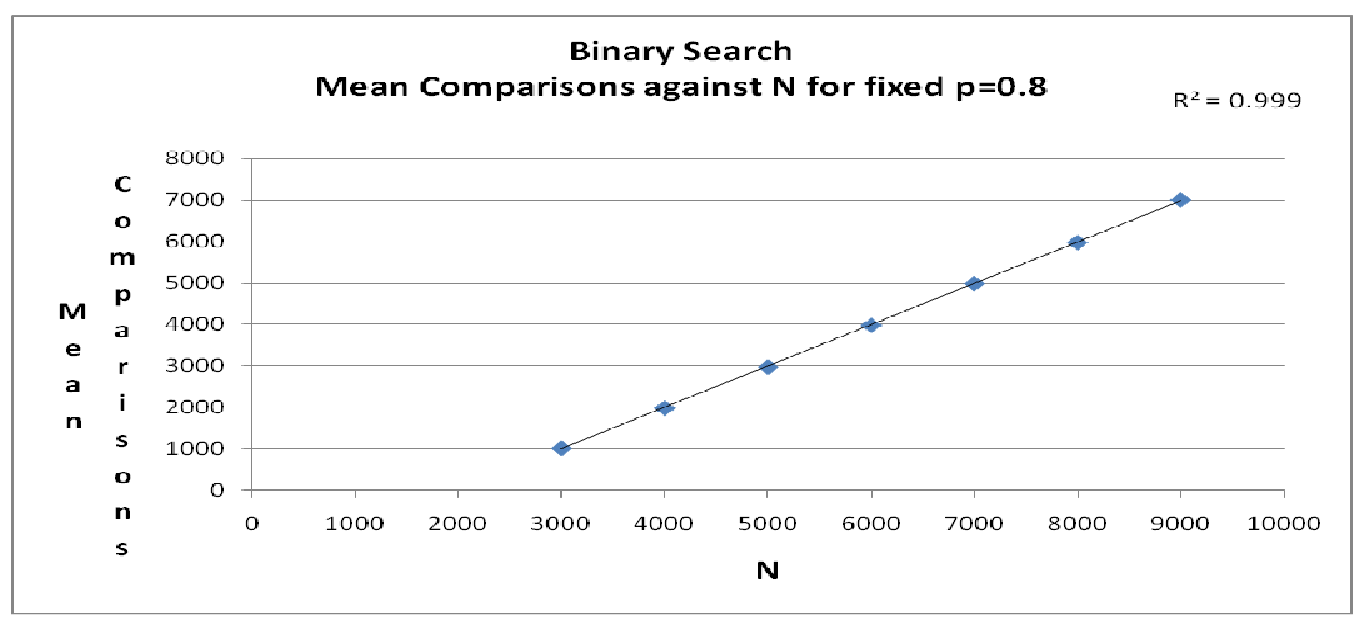

Fig. 6 Plot between $\mathrm{N}$ and mean comparisons for binary search $(\mathrm{p}=0.8)$ 


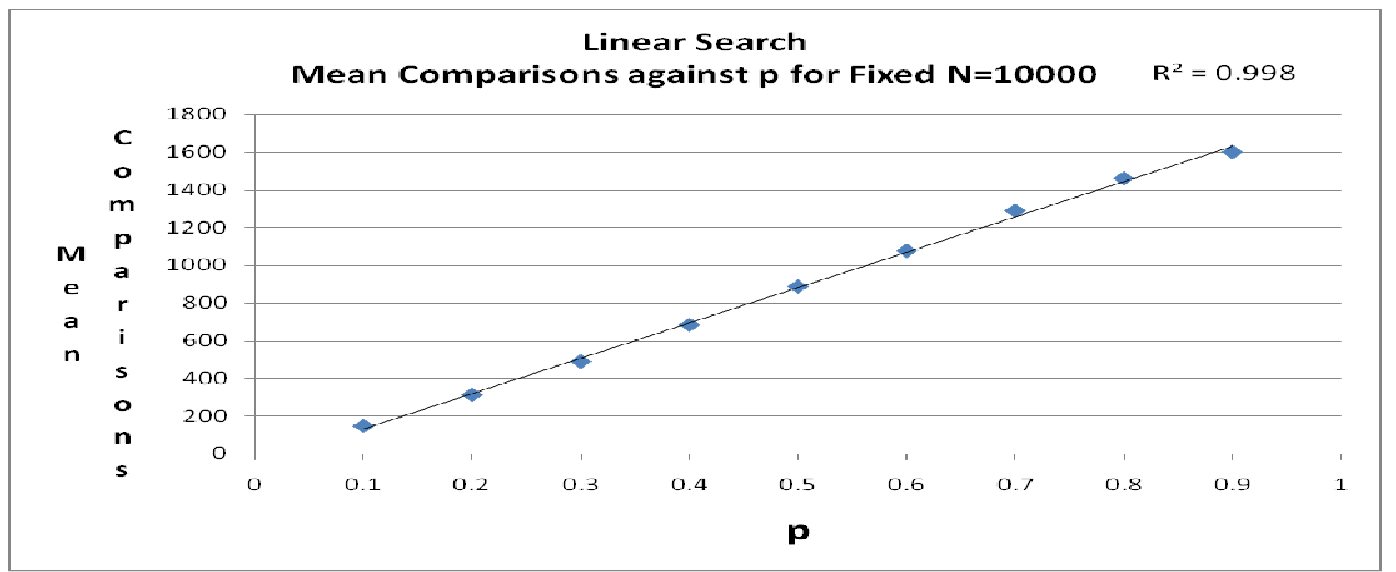

Fig. 7 Plot between $\mathrm{p}$ and mean comparisons for linear search $(\mathrm{N}=10,000)$

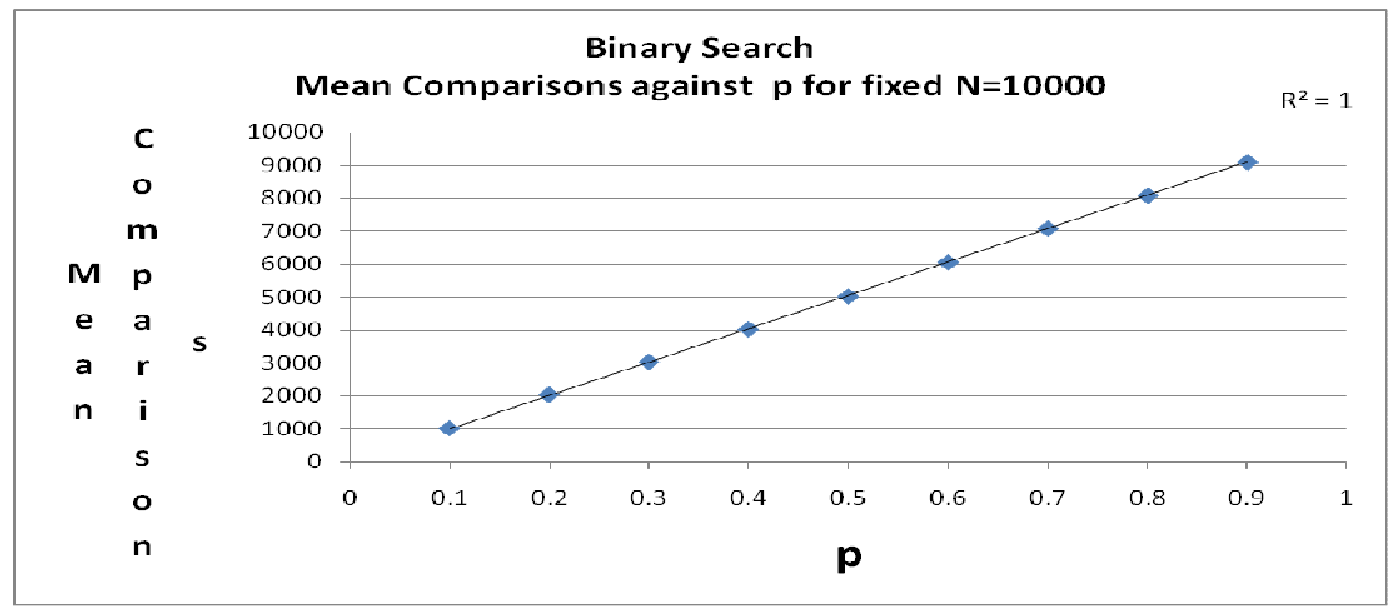

Fig. 8 Plot Between p and corresponding mean for binary search $(\mathrm{N}=10,000)$

\section{References}

[1] Knuth, D. E. The Art of Computer Programming, Vol. 3: Sorting and Searching, Addison Wesley, (1997), 3rd ed., 396-408

[2] Kumari , A. and Chakraborty , S., Software Complexity: A Statistical Case Study Through Insertion Sort, Applied Math. and Compu., vol. 190(1), (2007), p. 40-50

[3] Kumari, A. and Chakraborty, S., A Simulation Study on Quick Sort Parameterized Complexity Using Response Surface Design, International Journal of Mathematical Modeling, Simulation and Applications, Vol. 1, No. 4, (2008), 448-458

[4] Downey, Rod G.; Fellows, Michael R. (1999). Parameterized Complexity. Springer.

[5] S. C. Gupta and V. K. Kapoor, Fundamentals of Mathematical Statistics, Sultan Chand and Sons, New Delhi, reprint 2010 